International Scientific-Pedagogical Organization of Philologists "WEST-EAST" (ISPOP). Scientific Journal WEST-EAST. Vol 1/1 N1 (October, 2019). C. 23-27. doi:

Information about the author: Luiza N. Gishkaeva- PhD, Associate Professor of Department of Foreign Languages of the Philological Faculty of RUDN University;

Research interests: semantics, phraseology, cultural linguistics, intercultural communication, textology

e-mail: adv88-02@mail.ru

Сведения об авторе: Гишкаева Луиза Нахидовна - кандидат филологических наук, доцент, Российский университет дружбы народов

e-mail: $\underline{\operatorname{adv} 88-02 @ \text { mail.ru }}$

Information about the author: Olga V. Lomakina - Doctor of Philological Sciences, professor of the Department of Foreign Languages, Faculty of Philology, the Peoples' Friendship University of Russia, Professor of the Department of Modern Russian Language at St. Tikhon's Orthodox Humanitarian University (Russia). e-mail: rusoturisto07@mail.ru

Сведения об авторе: Ольга Валентиновна Ломакина - доктор филологических наук, профессор, Российский университет дружбы народов, Православный Свято-Тихоновский гуманитарный университет (Россия) e-mail: rusoturisto07@mail.ru

DOI:

\title{
COMPARATIVE RESEARCH OF TURKISH LANGUAGES (KAZAKH, TURKISH AND UZBEK) IN THE HISTORICAL ASPECT
}

\author{
Aigul Baituova \\ Ph.D, Associate Professor \\ Khoja Akhmet Yassawi International Kazakh-Turkish Univesity, Turkestan, Kazakhstan \\ (Turkestan, Kazakhstan) \\ e-mail: baituaigul@mail.ru
}

\begin{abstract}
A detailed study of the complex issue of differentiation and integration of Turkic languages, both in general Turkic and regional plans, is of great interest for Turkic studies. Naturally, when studying the structure of a language, each researcher had his own approach to their study and interpretation. This sometimes makes it difficult to compare studies of different authors, sometimes studies are contradictory. In Turkology, there are still no developed scientific methods for comparative study of large representatives of different genetically independent groups in this case - Kypchak, Oguz and Karluk - which are Kazakh, Turkish and Uzbek languages. In a number of comparative studies existing in Turkology, including in the studies of the phonetic structure of groups of closely related Turkic languages, a scientifically developed unified methodological approach is not always present. Information previously obtained by different authors of research results for different purposes can be characterized as general, inconsistent, fragmentary, which do not represent especially composed essays, built according to a specific plan. The purpose of this characteristic with a brief insight into the processes of the studied languages formation is an attempt to link the current state of the language with their historical process of formation and ongoing development. Historical, ethnic, social, demographic, cultural, administrative, territorial-geographical and other objective factors are undoubtedly decisive, leaving their definite imprints in the language development of the ethnic group. At the same time, deviations in the structure of the studied languages from the Pra-Turkic state find a well-known explanation also in extraordinary situations of history.
\end{abstract}

Keywords: research, comparative, Turkology, formation

\section{СРАВНИТЕЛЬНО-СОПОСТАВИТЕЛЬНОЕ ИССЛЕДОВАНИЕ ТЮРКСКИХ ЯЗЫКОВ (КАЗАХСКОГО, ТУРЕЦКОГО И УЗБЕКСКОГО) В ИСТОРИЧЕСКОМ АСПЕКТЕ}

\author{
Айгуль Байтуова \\ к.ф.н., доцент \\ Международный казахско-турецкий университет им. Х.А Ясави, \\ (Туркестан, Казахстан) \\ e-mail: baituaigul@mail.ru
}

\begin{abstract}
Аннотация. Для тюркологии представляет большой интерес детальное исследование сложного вопроса дифференциации и интеграции тюркских языков как в общетюркском, так и в региональном планах. Естественно, каждый исследователь при изучении структуры того или иного языка имел свой собственный подход к их изучению и интерпретации. Это порой затрудняет сравнение исследований разных авторов, иногда исследования оказываются противоречивыми. Выработанных
\end{abstract}


научных методов сравнительного изучения крупных представителей разных генетически самостоятельных групп в данном случае - кыпчакской, огузской и карлукской, какими являются казахский, турецкий и узбекский языки, в тюркологии пока еще нет. В ряде существующих в тюркологии сравнительных исследований, в том числе в исследованиях фонетической структуры групп близкородственных тюркских языков, не всегда присутствует единый, научно разработанный методический подход. Сведения, ранее полученные разными авторами результатов исследований для разных целей, можно характеризовать как общие, непоследовательные, фрагментарные. Целью подобной характеристики с кратким экскурсом в процессы становления и формирования изучаемых языков является попытка увязать современное состояние языка с их историческим процессом становления и поступательного развития. Исторические, этнические, социальные, демографические, культурные, административные, территориально-географические и другие объективные факторы являются, несомненно, решающими, оставляющими в языковом развитии этноса определенные отпечатки. Вместе с тем отклонения в структуре изучаемых языков от пратюркского состояния находят известное объяснение также в экстраординарных ситуациях истории.

Ключевые слова: исследования, сравнительный, тюркология, формирование

ВВЕДЕНИЕ. Исследование тюркских языков и диалектов в тюркологии имеет относительно небольшую историю по сравнению с индоевропеистикой. Здесь в первую очередь следует упомянуть работу “Фонетика северных тюркских языков” и другие фундаментальные труды выдающегося языковеда академика В.В. Радлова (1882), являющегося основателем российской тюркологии и представлявшего в ней научное направление, которое отличалось от миссионерского направления, представленного в известной работе “Алтайская грамматика". Известно, что каждый из современных тюркских языков формировался в результате длительного процесса структурного развития, отработки и постоянного совершенствования литературных (письменноорфографических, речевых и др.) норм. В этом процессе, пожалуй, одним из главных факторов становления языка, его собственных норм и строевых элементов становится избранная и выработанная им же фонетическая система.

В этой связи представляет несомненный интерес не только объединяющие и сближающие черты этих языков, но и их отличительные свойства, что выработалось в результате самостоятельного развития этих языков в различных социально-экономических, исторических, административно-государственных и естественногеографических условиях.

Если же в указанных выше регионах ранее представители трех языков в виде близкородственных родоплеменных объединений или союзов долгие годы жили в тесном контакте (например, будущие представители казахского и узбекского народов до образования самостоятельных государств составляли единую этническую массу, а представители огузской группы - турки находились с казахским в одном огузо-кыпчакском родоплеменном союзе), то после их преобразования в самостоятельные народы произошли серьезные сдвиги в структуре их языков. «История знает периоды, когда племена и роды, образовавшие казахский и узбекский народы, общались на одном общем языке, а письменно литературный язык кыпчакско-огузских племенных объединений (VIII-IX вв.) в Средней Азии в раннем средневековье был общим для представителей этих этнических групп, о чем свидетельствуют письменные памятники этого периода» (1989).

В этой связи несомненный интерес представляет история образования каждого из рассматриваемых языков как в плане выяснения объективных (историко-этнических, административно-территориальных, демографических и др.) факторов, так и конкретных этнолингвистических и других ситуаций.

Генетическое родство и современная близость языков одной системы не одно и то же. Общность, гомогенность происхождения языков не всегда гарантирует их структурную идентичность, однообразие, адекватность. Многовековая история развития тюркских языков благоприятствовала их консолидации, приобретению ими групповой общности, вместе с тем история способствовала их дифференциации, размежеванию, разобщению, приобретению множества различительных признаков. Это общая закономерность развития родственных языков.

Для тюркологии представляет большой интерес детальное исследование сложного вопроса дифференциации и интеграции тюркских языков как в общетюркском, так и в региональном планах. Известно, что в истории становления и развития указанных языков на самом раннем этапе было множество объективных факторов, благоприятствовавших их сближению и выработке общих литературных черт и фонетикоорфографических норм, которые, например, имеют ныне турецкий и азербайджанский языки, казахский, каракалпакский и ногайский языки, узбекский и уйгурский языки.

ОБЗОР ИСТОРИИ И ДИСКУССИЯ. Современный казахский язык (Қазақ тілі), на котором в мире говорят около 18 миллионов человек, является государственным языком Республики Казахстан и обслуживает население республики, говорящее на казахском языке, а также одну треть общего числа казахов, проживающих за пределами Казахстана (Tatimov 1992).

В периодизации истории казахского этноса и его языка ученые выделяют несколько периодов. Древний период истории казахского этноса “охватывает время с II в. до н.э. по V в.н.э. Родо-племенные объединения усуней и канглы явились преемниками сакского этнокультурного наследия, имели свою государственность (канлы и уйсун) и находились в тесных политических контактах и этнических связях с хуннами (гуннами), юечжани, аланами, древними китайцами и с другими сопредельными и отдаленными этносами. Состояние 
праказахского языка на этом этапе истории почти не изучена, вследствие крайней ограниченности фактического материала, равно как и недостаточного совершенства методики исследования“ (там же).

Если о первом этапе истории казахского языка из-за отсутствия засвидетельствованных письменных источников можно говорить лишь априори, то о втором периоде истории казахского языка можно говорить уже более конкретно, сопоставляя его данные с фактами дошедших до нас и хорошо изученных опубликованных памятников древнетюркской письменности.

“Второй этап истории становления языка казахского этноса падает на раннесредневековый период (c VI по IX вв.) и связан с эпохой образования и расцвета Тюркского каганата и создания орхонских, енисейских и таласских рунических памятников” (1946).

Говоря о раннесредневековом периоде истории казахского языка, ученые отмечают, что языки известных племен и племенных объединений, вошедших затем в этническую структуру казахского народа, имели немало схожих черт с тюркским литературным языком VI-IX вв. Древнетюркское койне представляло собой синтез живых языков и диалектов множества тюркских племен, в том числе кыпчакских, огузских и карлукских, живших в тот период на огромных просторах Центральной Евразии, в том числе и Казахстана. Это был живой и богатый язык, многие его образцы в виде устно-поэтического творчества народа преемственно связаны с традициями древнетюркских памятников.

С падением Тюркского каганата и расширением сферы политического и культурного влияния мусульманского мира в Средней Азии и Казахстане происходят значительные перемены, которые оказали заметное влияние на языковую ситуацию в этих регионах.

Среди множества родо-племенных языков и наречий, генетически восходящих к общему истоку, кыпчакский компонент к XIV-XV вв. стал подавляющим, и кыпчакская группа языков в средние века широко функционировала как в Средней Азии и Казахстане, так и в Поволжье и Закавказье, а также в Венгрии, Мамлюкском Египте и Сирии. Уже тогда можно было говорить о языке тюрков Дешт-и Кыпчака, что в скором времени привело к образованию ряда самостоятельных языков: казахского, ногайского, татарского и др. Таким образом, кыпчакская общность (X-XV вв.) играла роль аккумулирующей и интегрирующей среды, смогла объединить и сформировать типологически компактную, структурно цельную, лексически богатую и самобытную кыпчакскую группу тюркских языков. С этим процессом тесно связано и сложение казахского народа, его языка, этническое самосознание казахов и образование государственности на казахской земле.

«В обширном владении Золотой Орды, простиравшемся от Дешт-и Кыпчака до пределов Мамлюкского Египта и Сирии в XIII-XIV вв. функционировал общий кыпчакский литературный язык, имевший в разных регионах свои локальные разновидности, отличавшиеся диалектным разнообразием. Основным ядром формирования этого общекыпчакского литературного языка в географическом представлении был Дешт-и Кыпчак, а в языковом отношении собственно кыпчакско-куманский диалект, который выступал в тот момент как доминирующий компонент всей кыпчакской группы тюркских языков» (Курышжанов 1973).

Что же касается казахского языка, то он с этим компонентом имел прямую этногенетическую и этноязыковую связь.

Перечень письменных памятников средневековья дает полное представление о том, в каких сложных ситуациях складывался казахский язык, сохранив при этом присущий только ему собственный облик, как утверждают ученые. В этом важную роль сыграли три фактора: а) собственная природа родо-племенных языков, составивших его структурную основу; б) фактор преемственности его развития с древнейшими языками; в) фактор влияния на него окружающей языковой и этнокультурной среды, в том числе и влияние огузского и карлукского компонентов.

Заслуживает внимания подробное рассмотрение результатов каждого из этих факторов в отдельности. Отметим некоторые основные моменты указанных факторов.

Во-первых, казахский язык сложился на основе этнически близких, но далеко не гомогенных этнических элементов, чем и объясняется его быстрое сложение и структурная монолитность. Этими же особенностями объясняется значительное (фонетическое, лексико-грамматическое) сходство языков кыпчакской группы.

Во-вторых, структурная близость казахского языка с древними языками, как считают ученые, продиктована мобильностью образа жизни казахского кочевого общества, духовной, религиозной, этнокультурной преемственностью, а также общностью их устно-поэтических традиций и другими факторами.

В-третьих, в жизни казахских племен происходили различные события, имевшие свое влияние на формирование и развитие казахского языка. Но самыми ощутимыми факторами, повлиявшими на его становление и развитие, были факторы языкового окружения и длительные контакты с другими языками. В этом плане можно было бы назвать, например, влияние не только близкородственных тюркских языков и племен, но и влияние арабского, иранского, славянского, монгольского, китайского и др. соседних языков. Все эти факторы иной языковой среды, естественно, определенным образом имели свое воздействие на формирование особенно фонетической структуры и функционирование фонетических закономерностей казахского языка. При этом контакты родственных внутри кыпчакской группы языков, как правило, приводили к взаимопроникновению их структурных элементов и выработке общих типологических черт, тогда как контакты казахского языка не с кыпчакскими (огузскими, сельджукскими, карлукскими и др.) языками - к привнесению в него собственных элементов. Следует отметить, что подобные контакты древних казахских племен с гуннами, саками существовали еще в древности. 
В историческом процессе формирования казахского языка определенную роль сыграли и славянские языки, так же, как и тюркские, - в славянских языках. Это происходило благодаря соседству России и Дешт-иКыпчака, а в последующие периоды - с Золотой Ордой, затем - с вновь образованными ханствами, в том числе с Казахским ханством (1466 г.). Казахско-русские языковые контакты продолжались и усилились после присоединения Казахстана в состав России (1731 г.) в результате проведения царизмом колониальной политики, открыто преследовавшей цель ассимиляции казахского языка. Такая же политика, но несколько в иной форме продолжалась и в условиях СССР (с 1917 г. по 1991 г.).

Состояние родо-племенных языков и диалектов характеризуется, прежде всего, их самостоятельным функционированием в течение многих столетий. В силу природно-географических условий, геополитических факторов в дальнейшем происходит их постепенное сближение (а не расхождение) в рамках кыпчакской языковой общности. Этот процесс продолжался до тех пор, пока на рубеже XV-XVI вв. окончательно не сложился казахский общенародный язык во всех своих структурных звеньях. И это произошло постепенно путем консолидации вокруг себя всех родо-племенных языков и диалектов и в результате нивелировки их различий и выработке общих грамматических, произносительных, лексических и др. норм. В этом историческом процессе внутреннего саморазвития «казахский язык уже в первой половине ХІХ в. достигает относительно идеального состояния - своего единства и общности в функционировании, структурной целостности и монолитности, национальной самобытности» (Isaev 1996). Это говорит о том, что «литературный язык казахов созревал в недрах общенародного языка и окончательно сформировался во II половине XIX в» (Abilhasimov 1983).

По поводу устной и письменной форм литературного языка казахов существует разное мнение. Одни ученые считают, что казахский литературный язык сформировался сначала в устной форме и созревал в недрах общенародного языка и развивался благодаря творческой деятельности выдающихся казахских певцовжырауов, акынов-импровизаторов, устному народному творчеству, опережая тем самым его письменные формы. Этот язык звучал еще в XIV-XVI вв. в ханских дворцах и на народных собраниях.

Таким образом, современный казахский письменный- литературный язык, развивающийся в статусе государственного, учеными признан как один из развитых, богатых исконно-историческими традициями относительно чистых и является цельным и монолитным для всего казахского общества тюркских языков кыпчакской группы.

Современный турецкий язык (Türk dili, Türkçe), на котором говорит (по данным 1999 г.) около 80 миллионов человек, является государственным языком Турецкой Республики (Esnazarov, Temirbekov 1999). По мнению многих исследователей, он сложился в результате многовекового процесса развития языков огузосельджукских племен, проникших в X-XI вв. из Средней Азии на Анатолийский полуостров и сформировавших там в XII в. государство Сельджукидов, а позже, в XIV в., - Османское государство, ставшее затем Османской империей. Именно в этот период началось становление турецкой народности и турецкого языка. До прихода к власти Мустафы Кемаля Ататюрка турецкий язык назывался османским.

«Среди языков тюркской семьи турецкий язык признан одним из наиболее изученных» не только со стороны самих турецких ученых, но и ученых России и ряда зарубежных стран (Кононов 1976). Он «обладает множеством исследованных и документированных памятников письменности, самые ранние из которых относятся к XIV в» (Kamalov 1955).

По ряду фонетико-морфологических и лексических признаков турецкий язык сравнивается с азербайджанским, туркменским и гагаузским языками и вместе с ними образует особую группу, которая согласно классификации обозначается как “юго-западная” группа тюркских языков, или -по названию племен “огузов” - “огузская группа языков”. Эта группа языков, по мнению исследователей, сыграла большую роль в формировании не только турецкого, но и азербайджанского, туркменского и гагаузского языков и общее количество носителей этих языков составляет около 100 миллионов человек. Таким образом, огузская группа среди других групп тюркских языков занимает доминирующее положение по числу говорящих на этих языках людей.

По сведениям исследователей, в тюркологии установлено три основных этапа развития османского языка: 1) период “староосманского языка" (Eski Osmanlica) - XIII-XV вв., 2) период “среднеосманского языка" (Orta Osmanlica) - XV-XIX вв. 3) эпоха “новоосманского языка" (Yeni Osmanlica) - XIX-XXI вв.

Эпоха “староосманского языка” связана с формированием турецкого языка из смешанных, типологически разнородных фонетических, лексических, морфологических и синтаксических элементов собственно турецкого языка с элементами арабского и персидского языков.

Эпоха “среднеосманского языка" характеризуется развитием “высокого” литературного стиля, который господствовал во всех сферах государственной деятельности, а также в литературе, науке, искусстве. В эту эпоху усилились роль и значение арабского языка, являвшегося языком ислама - государственной религии Османской империи. На арабском языке велось преподавание в религиозных школах - медресе. В среднеосманский период окончательно сложился основной пласт арабско-персидской лексики, занявшей в художественных произведениях “высокого” стиля до 90\% общего лексического фонда. Без серьезного изучения арабского и персидского языков в тот период было невозможно читать и писать “по-османски”.

Эпоха “новоосманского языка" связана с периодом османского реформизма - Танзимата (Tanzimat, 18391878 гг.) - и с эпохой младотурецкой революции (1908 г.). Передовые деятели османской культуры этого периода, такие как Намык Кемаль, Ахмет Митхат, Шемседдин Сами, Ибрагим Шинаси, позже Омер 
Сейфеддин, Зия Гёкалп и многие другие, искали пути преодоления разрыва между литературными и разговорными нормами османского языка. Они предлагали избегать употребления заимствованной арабской и персидской лексики при наличии в языке исконно турецких эквивалентов, выявить лексический фонд турецкого языка, реформировать его графику и орфографию, установить основы национального турецкого языка. Все эти реформы могли способствовать приобщению широких народных масс к образованию, устранению языкового барьера между “высоким” стилем и простым народным турецким языком.

Только после распада Османской империи и провозглашения Турецкой Республики (1923 г.) в Турции были созданы реальные условия для проведения реформ в области языка, получивших в турецкой лингвистике название “Dil Devrimi” (“Языковая революция”). Основными задачами языковой революции явились очищение лексики турецкого языка от иноязычной, в первую очередь от арабских и персидских заимствований, создание новой лексики на базе тюркских основ, перевод турецкого алфавита с арабской графики на преобразованную латинскую графику, нормализация и кодификация грамматических, стилистических и орфографических норм и правил. Новые социальные отношения в Турции требовали ликвидации элитарности литературного языка, демократизации письменных норм и сближения их с разговорным народным турецким языком.

Организатором движения за коренное реформирование турецкого языка выступил «основатель Турецкой Республики Мустафа Кемаль Ататюрк. В первую очередь термин “Osmanlica” (“османский язык”) был заменен термином “Turkçe” (“турецкий язык”). Затем в 1928 г. последовала реформа турецкого алфавита, перевод его с арабской графики на латинскую. В 1929 году было отменено преподавание во всех турецких школах арабского и персидского языков» (Melikov1998).

Очищение турецкой лексики от арабских и персидских заимствований, известное под названием "оzleşme” - “очищение от чуждых элементов”, осуществлялось путем отбора генетически тюркской лексики из письменных литературных памятников с XIII в. (Tarama); отбора лексики из диалектов турецкого языка (Derleme); создание новых слов (Türetme). Следует отметить, что неологизмы, созданные посредством словообразовательных средств турецкого языка, со временем вытеснили иноязычные заимствования и значительно обновили современный турецкий литературный язык. Многие из них прочно вошли и в разговорную речь.

В становлении и развитии нового турецкого литературного языка особая роль принадлежит Назиму Хикмету - основоположнику новой турецкой поэзии, который в произведениях, созданных еще в 20-е годы ХХ века, отказался от высокого, изысканного стиля, внедрил в поэзию язык улиц и городское просторечие.

Следует отметить, что в процессе сложной истории формирования и развития турецкого языка и его литературной формы известные изменения претерпела и его фонетическая структура. В ней произошли определенные сдвиги в ту или иную сторону, установились собственные нормы фонем в вокальной и консонантной системе, определилась устойчивость тех или иных фонетических закономерностей. Это создает необходимую базу для сравнительно-исторической характеристики фонемного состава и фонологических закономерностей турецкого языка с казахским и узбекским языками.

Современный узбекский язык (Ўзбек тили), на котором говорит около 38 миллионов человек, является государственным языком Республики Узбекистан. Узбекский язык относится к юго-восточной ветви, т.е. к карлукской группе тюркских языков. Основная часть узбекского народа живет в Узбекистане. Помимо Республики Узбекистан, довольно большие группы узбеков проживают в Таджикистане, Казахстане, Кыргызстане, Туркменистане и других государствах - бывших республиках СССР. Кроме того, узбеки живут в Афганистане (около 1200 тыс.чел.) и Синьцзян-Уйгурском автономном районе КНР (бывший Восточный Туркестан - около 15 тыс.чел.)

Узбекский язык, как и многие тюркские языки, сформировался в XIV-XVI вв., а его современная литературная форма - после Октябрьской революции (1917 г.).

«Узбекский язык, функционирующий как государственный язык Республики Узбекистан, имеет в целом или в разных регионах узбекско-русское двуязычие. Среди узбеков широко распространено также узбекскотаджикское двуязычие, которое в последние годы СССР приобрело форму трехъязычия, где третьим компонентом выступал русский язык» (Hodzhiev 1997). Надо отметить и то, что узбекская диаспора, живущая за пределами Узбекистана, пользуется узбекско-казахским, узбекско-киргизским, узбекско-уйгурским и др. видами двуязычия.

Узбекский язык имеет многовековую письменную традицию, которая была тесно связана с периодом развития чагатайского литературного языка в XV-XVI вв., именовавшегося также “среднеазиатско-турецким”, “средневековым среднеазиатским тюркским литературным языком”, “староузбекским языком XV-XVI вв.”. В эти периоды развития узбекский язык, как и многие тюркские языки Средней Азии и Казахстана, пользовался арабским письмом, затем - латинизированным алфавитом, а с 1939 года была введена в языковую практику письменность, основанная на кириллице. О периодизации истории узбекского языка существуют различные мнения. Самой приемлемой, как считают узбекские ученые, «представляется следующая периодизация:

1) староузбекский (XII-XIVвв.);

2) среднеузбекский (XIV-XVIвв., язык произведений Алишера Навои);

3) новоузбекский (XIX в. - начало XX в.);

4) современный узбекский литературный язык» (Hodzhiev 1997).

Каждый из этих периодов развития узбекского языка характеризуется своими особенностями, как внутриязыковыми, так и результатами воздействия внешних факторов. Ученые отмечают, что узбекский язык 
претерпевал определенное влияние в результате длительных контактов с иранскими языками и диалектами, арабским и русским языками, не говоря уже об интенсивном процессе смешения со многими тюркскими племенами Средней Азии и Казахстана.

Естественно, в результате этих процессов в узбекский язык больше всего вошли не только лексические, но и грамматические элементы иранских языков. Начиная с XIX в., в узбекский язык интенсивно начинают проникать заимствования через русский язык.

Принято считать, что в истории формирования узбекского языка сыграли важную роль этническая конгломерантность и гетерогенность его носителей. Ученые отмечают, что в образовании общенародного узбекского языка на всем протяжении истории его становления и развития принимали участие три крупных наречия, которые объединяют ряд диалектов и групп говоров: 1) карлукское наречие, 2) кыпчакское наречие; 3 ) огузское наречие.

Узбекский ученый Ф.К.Камалов, используя данные истории, археологии и этнографии, в своей работе пишет что «узбеки являются одной из древнейших народностей Средней Азии, которые жили на территории современного Узбекистана» (Kamalov 1955). Ссылаясь на историю Узбекистана, он отмечает, что “узбекский народ формировался как тюркоязычный народ на территории Узбекистана за много веков до появления в оседлых районах Средней Азии кочевников-узбеков, хотя и не носил их имена» (Kamalov 1955). «Следовательно, узбекский язык, выработанный еще задолго до появления узбеков-кочевников, с течением времени постепенно расширяется и развивается. Кочевники - узбеки в процессе перехода на оседлый быт воспринимают культурное наследие, а также языковые особенности основного местного населения» (Kamalov 1955). Об этом же свидетельствуют следующие высказывания Ф.К.Камалова: «о том, что, несмотря на самостоятельное и историческое образование, узбекский народ имеет языковое родство с казахами, киргизами, каракалпаками, туркменами, а также с другими тюркоязычными народностями. Когда речь идет о языковом родстве тюркоязычных народностей, следует особо выделить среди них те, которые переплетены в территориальном, экономическом, политическом и культурном отношениях, каждый из языков являет собой сложное своеобразное историческое образование, и они отличаются друг от друга по своему словарному составу и грамматическому строю» (Kamalov 1955).

Хотя у узбеков с тюркоязычными народностями имеется общая принадлежность к одной языковой системе, однако, согласно другим данным, узбеки стоят ближе к таджикам. “Таджики и узбеки - наиболее древние из культурных народов Средней Азии, их история связана с Согдом, Хорезмом, Бактрией, Ферганой, Шашем, на территории которых находились очаги богатой в древности цивилизации” (ИНУ 1950).

“История сложения таджикского и узбекского народов охватывает десятки веков и охватывает целый ряд племен и народностей. Своеобразный процесс сложения таджикского и узбекского народов нашел отражение в их языковом строительстве. Узбекский язык испытал влияние таджикского языка, а таджикский - узбекского языка" - заключает автор (там же).

Сказанное выше подтверждает существующее в тюркологии мнение о том, что узбекский язык сформировался на основе двух этнолингвистических источников - собственно тюркского и иранского (таджикского), что, естественно, повлияло на исторический процесс становления структурных единиц узбекского литературного языка.

На формирование узбекского общенародного и литературного языка большое влияние оказывали не только ираноязычные и арабоязычные племена, но и племена тюркского происхождения, периодически прибывавшие на земли, заселенные узбеками, в разные исторические периоды.

ВЫВОДЫ И ЗАКЛЮЧЕНИЕ. Общие сведения, относящиеся к истории становления и развития казахского, турецкого и узбекского - трех сравниваемых языков, относящихся к трем разным - кыпчакской, огузской и карлукской - группам тюркских языков, дают основание сделать следующие выводы.

1. Все три языка по своей генетической природе являются исконно тюркскими, хотя в их образовании и развитии частичное участие принимали элементы негомогенного характера. Это относится в первую очередь к иранским элементам в узбекском языке.

2. Период становления и формирования литературных норм сравниваемых языков относится примерно к одной и той же исторической эпохе - к средневековью (XIV-XVI вв.).

3. Этнолингвистическую основу каждой из сравниваемых языков составляет определенная группа родов и племен, консолидировавшихся в одно этническое общество благодаря их административно-территориальной, природно-географической, культурно-традиционной и языковой общности.

4. Указанные группы языков в своем историческом развитии довольно тесно контактировали между собою территориально, географически и, перемешиваясь, часто перекрещивались в своем структурном развитии, что привело к взаимопроникновению их языковых элементов.

5. Хорошо прослеживаются контакты между всеми тремя языками, однако более интенсивным взаимным контактам подверглись по ряду причин казахский и узбекский языки. Тесный исторический контакт между турецким и двумя среднеазиатскими - казахским и узбекским - языками в силу определенных объективных причин значительно ослаб. 


\title{
LIST OF REFERENCES
}

Abilhasimov B. Kazahskiy literaturnyy yazyk vtoroy poloviny HIH v. (na materiale kazahskoy pechati): avtoref.... dokt. filol. nauk. Alma - Ata. 1983 - 6 s.

Bartol'd V.V. Istoriya turecko - mongol'skih narodov. - Tashkent, 1928. - S. 6, 29.

Bernshtam A.N. Social'no - ekonomicheskiy stroy orhono - eniseyskih tyurok VI - VIII vv. Vostochnotyurkskiy kaganat i kirgizy. M., L., 1946. $-82 \mathrm{~s}$.

Esnazarova Ұ.A., Temirbekov A.T. Tүrki tildes elder geografiyasy. Ahmet Iasaui Universitetiniң Zhərdem Kory Baspasy. - Ankara, 1999. -S. 69, $107 \mathrm{~s}$

Isaev S. Қазақ әdebi tiliniң tarihy. - Alma - Ata, 1996. - 81s. INU-Istoriya narodov Uzbekistana. - Tashkent, 1950. t. I, 8 - S.11, 29, 43.

Kaydarov A.T. Kazahskiy yazyk // Yazyki mira. Tyurkskie yazyki. - Bishkek, 1997. - 242 s.

Kamalov F.K. Istoriya stanovleniya i razvitiya uzbekskogo nacional'nogo yazyka. - Tashkent, 1955. -S. 44

Kononov A.N. Ocherk istorii izucheniya tureckogo yazyka. - L., 1976. - 115 c.

Kuryshzhanov A.K. Yazyk starokypchakskih pis'mennyh pamyatnikov. Avtoref. na sois. uch. st. dok. filol. nauk. - Alma - Ata, 1973. - S.51-52.

Melikov T. Literatura Turcii. Korni i korona. - M., 1998. - 138 s.

Nadzhip E.N. Issledovaniya po istorii tyurkskih yazykov HI - XIV vv. - M., 1989. - 32 s.

Radlov V.V. Fonetika severnyh tyurkskih yazykov. - Leypcig, (na nemec. yaz.), 1882. Sevortyan E.V. Fonetika tureckogo

literaturnogo yazyka. - M., 1955. - $134 \mathrm{~s}$.

Tatimov M. Наاуқ - nama nemese San men Sana. - Almaty: Zhazushy, 1992.- 17 s.

Hodzhiev A.P. Uzbekskiy yazyk. Yazyki mira. Tyurkskie yazyki. - M., 1997. - S. 426 - 427.

\section{For citation:}

Baituova, A. (2019) COMPARATIVE RESEARCH OF TURKISH LANGUAGES (KAZAKH, TURKISH AND UZBEK) IN THE HISTORICAL ASPECT. International Scientific-Pedagogical Organization of Philologists “ WEST-EAST ” (ISPOP). Scientific Journal WEST-EAST. Vol 1/1 N1 (October, 2019). pp. 27-33. doi:

\section{Для цитирования:}

Байтуова, А. (2019) СРАВНИТЕЛЬНО-СОПОСТАВИТЕЛЬНОЕ ИССЛЕДОВАНИЕ ТЮРКСКИХ ЯЗЫКОВ (КАЗАХСКОГО, ТУРЕЦКОГО И УЗБЕКСКОГО) В ИСТОРИЧЕСКОМ АСПЕКТЕ // International Scientific-Pedagogical Organization of Philologists “WEST-EAST” (ISPOP) . Scientific Journal WEST-EAST. Vol 1/1 N1 (October, 2019). C. 27-33. doi:

Information about the author: Aigul Baituova - Ph.D, Associate Professor, Khoja Akhmet Yassawi International Kazakh-Turkish Univesity, Turkestan, Kazakhstan

e-mail: baituaigul@,mail.ru

Сведения об авторе: Айгуль Байтуова - к.ф.н., доцент, Международный казахско-турецкий университет им. Х.А Ясави, Туркестан, Казахстан

e-mail: $\underline{\text { baituaigul@mail.ru }}$

DOI:

\section{ABOUT FIXING OF THE LATEST PHRASEOLOGICAL UNITS IN DICTIONARIES OF RUSSIAN OF DIFFERENT TYPE}

\author{
Elena Generalova \\ Doctor of Philology, Assistant Professor \\ Saint-Petersburg State University \\ (Saint-Petersburg, Russia) \\ e-mail: elena-generalova@yandex.ru
}

\begin{abstract}
The purpose of the present article is a research of lexicographic representation of phraseological innovations in Russian. The methods and types of lexicographic interpretation of new phraseological units in dictionaries of modern Russian of different type (explanatory, neological, phraseological, dictionaries of slang and colloquial speech) are compared.The material of the research is presented by the latest phraseological units which appeared in Russianrecently (in the end of the 20th-beginning of the 21st century), among which the latest idiomaticswith many loans, jargon units, periphrases, steady comparisons and new paremias. The concept of a phraseological neologism and ways of fixing of the latest phraseological units in the dictionaries of different type are discussed. As a result of the research it was found out that lexicographic interpretation of phraseological innovations is directly connected with their lexical and grammatical status and tasks of the dictionary. In the Russian lexicography there is no such type of the dictionary as the dictionary of phraseological neologisms, and in article attention is paid to the concept of this type of the dictionary.
\end{abstract}

Keywords: phraseological unit, neologism, lexicography, modern Russian, lexicology 